\title{
Potensi Ekonomi Pemanfaatan Lahan Pekarangan di Desa Tambakrejo Kecamatan Jombang Kabupaten Jombang
}

\section{Economic Potential of Yardland Utilization in Tambakrejo Village, Jombang District, Jombang Regency}

\author{
Rinto Siswantoro ${ }^{1}$, Anggi Indah Yuliana ${ }^{2}$ \\ ${ }^{1}$ Program Studi Agribisnis Fakultas Pertanian \\ ${ }^{2}$ Program Studi Agroekoteknolgi Fakultas Pertanian \\ Universitas KH. A. Wahab Hasbullah Jombang
}

\section{ARTICLE INFO}

Article history:

DOI:

10.30595/pspfs.v2i.207

Submitted:

July 29, 2021

Accepted:

Sept 10, 2021

ABSTRACT

This study aims to 1) find out the form of yardland use 2) find out the amount of initial capital used in the utilization of yardland 3) find out how much the contribution of yardland use in addition to household economic income. This research was conducted in Tambakrejo Village, Jombang District, Jombang Regency, using purposive sampling from February to June 2021. The number of samples in this study amounted to 96 respondents. This study shows 1) the form of utilization of yardland conducted by the community is covering agriculture/plantations, farms, and other business entities 2) The amount of capital used in the utilization of yardland starting from Rp. 500.000,. - Rp. 1.500.000,. 3) The utilization of yardland contributes to improving the household economy and daily needs.
\end{abstract}

Published:

Nov 10, 2021

Keywords:

Economic Potential, Tambakrejo Village, Yardland
This work is licensed under a Creative Commons Attribution 4.0 International License.

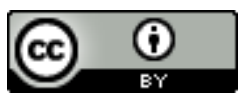

Corresponding Author:

Rinto Siswantoro

Program Studi Agribisnis Fakultas Pertanian

Universitas KH. A. Wahab Hasbullah Jombang

Email: siswantororinto@gmail.com

\section{PENDAhuluan}

Pekarangan adalah lahan sempit di sekitar pemukiman. Hampir diseluruh rumah penduduk Indonesia memiliki sebidang lahan kosong untuk dijadikan sebuah pekarangan. Sebagian besar masyarakat penduduk Indonesia memanfaatkan pekarangannya untuk tempat parkir kendaraan pribadi, jemuran pakaian, dan juga tempat tumbuhnya tanaman liar yang difungsikan hanya sebagai peneduh sekitar lahan pekarangan tersebut dari teriknya sinar matahari. Padahal pekarangan memiliki potensi untuk digunakan sebagai kegiatan ekonomi dan juga pemenuhan kebutuhan rumah tangga.

Pada masa pandemi covid19 yang berdampak pada penurunan pendapatan masyarakat akibat kebijakan seperti PSBB, WFH (work from home), PHK dan lain-lain, pekarangan bisa dijadikan sebuah solusi bagi masyarakat untuk memenuhi kebutuhan dengan memanfaatkannya menjadi sebuah kegiatan ekonomi yang menghasilkan. Pemanfaatan lahan pekarangan yang dibuat dalam meningkatkan pendapatan rumah tangga dan dapat juga diarahkan terhadap komoditas komersial yang memiliki nilai ekonomi tinggi, seperti buah, sayuran, 
biofarmaka, serta ternak dan ikan (Djamalu dkk., 2014). Lahan pekarangan memiliki fungsi multiguna, karena dari lahan yang relatif sempit dapat menghasilkan bahan pangan seperti umbi-umbian, sayuran, buah-buahan; bahan tanaman rempah dan obat, bahan kerajinan tangan; serta bahan pangan hewani yang berasal dari unggas, ternak kecil maupun ikan (Chanlis, 2019).

Desa Tambakrejo menjadi salah satu wilayah di Kecamatan Jombang, Kabupaten Jombang yang memiliki potensi dalam pengembangan usaha keluarga berbasis pekarangan. Banyaknya pondok pesantren dan sekolah di wilayah Desa Tambakrejo memberikan peluang usaha bagi warga dengan memanfaatkan lahan pekarangan. Fungsi ekonomi lanskap produktif pekarangan diantaranya mampu menunjang perekonomian keluarga dengan mengurangi pengeluaran belanja keluarga, produk pekarangan dapat dijual, dan pekarangan menjadi ruang usaha di rumah (Irwan dkk., 2018). Melihat kondisi diatas penelitian tentang potensi ekonomi lahan pekarangan sangat penting dilakukan di Desa Tambakrejo. Oleh karena itu, penelitian ini bertujuan untuk mengidentifikasi bentuk pemanfaatan lahan pekarangan yang dikembangkan oleh penduduk Desa Tambakrejo, mengetahui besaran modal awal yang digunakan dalam pemanfaatan lahan pekarangan, serta mengetahui seberapa besar kontribusi pemanfaatan lahan pekarangan sebagai tambahan pendapatan ekonomi rumah tangga.

\section{METODE PENELITIAN}

Penelitian ini dilaksanakan di Desa Tambakrejo Kecamatan Jombang Kabupaten Jombang pada bulan Februari sampai dengan Juni 2021. Pengambilan sampel ini menggunakan purposive sampling. Metode pengambilan sampel dengan purposive sampling adalah teknik penentuan sampel dengan pertimbangan tertentu (Sugiyono, 2012). Key informan dalam penelitian potensi ekonomi pemanfaatan lahan pekarangan di Desa Tambakrejo yaitu Kepala Desa. Metode yang digunakan untuk menentukan jumlah sampel dalam penelitian ini yaitu dengan menggunakan rumus slovin sebagai berikut:

$\mathrm{n}=\frac{\mathrm{N}}{1+\mathrm{Ne}^{2}}$

dimana:

$\mathrm{n}$ : Sampel

$\mathrm{N}$ : Populasi

1 : Konstanta

e : Batas Toleransi Kesalahan (Error Tolerance)

$\mathrm{n}=\frac{\mathrm{N}}{1+\mathrm{Ne}^{2}}$

$\mathrm{n}=\frac{2265}{1+(2265)(0,1)^{2}}$

$\mathrm{n}=\frac{2265}{1+(2265)(0,01)}$

$\mathrm{n}=\frac{2265}{23,65}$

$\mathrm{n}=95,7716702 \rightarrow 96$

$\mathrm{n}=96$ Orang

Dari hasil perhitungan jumlah sampel di atas maka diperoleh 96 orang sampel untuk masyarakat yang memiliki lahan pekarangan serta memanfaatkan lahan pekarangan tersebut yang ada di Desa Tambakrejo Kecamatan Jombang Kabupaten Jombang. Adapun metode pengumpulan data yang digunakan antara lain : 1) survei yaitu pengumpulan data dengan cara kunjungan langsung ke lahan pekarangan milik warga untuk mengamati bentuk pemanfaatan yang dikembangkan; 2) kuesioner yaitu pengumpulan data dengan memberi seperangkat pertanyaan tertulis kepada setiap responden; dan 3) dokumentasi yaitu pengumpul data dengan maksud untuk memperoleh data sekunder keadaan geografis \& demografis.

Teknik analisis data yang digunakan dalam penelitian ini adalah analisis data tabel presentase. Dimana data yang diperoleh akan disajikan dalam bentuk tabel, grafik, perhitungan modus dan mean yang kemudian dilakukan perhitungan presentase dengan tujuan memudahkan dalam mendeskripsikan data hasil dari penelitian. Perhitungan dengan rumus (Khairunnisa, 2018)sebagai berikut: 
$\%=\frac{\mathrm{n}}{\mathrm{N}}$

dimana:

$\%:$ Jumlah presentase yang diperoleh

$\mathrm{n}$ : Jumlah jawaban yang diperolah

$\mathrm{N}$ : Jumlah seluruh responden

Untuk menentukan kontribusi penerimaan dari pemanfaatan lahan pekarangan tanaman hortikultura terhadap total pendapatan keluarga, digunakan rumus sebagai berikut (Handayani dan Artini, 2009):

$P(\%)=\frac{Q x}{Q x+Q z} \times 100 \%$

dimana:

$\mathrm{P}(\%)$ : Kontribusi hasil pemanfaatan lahan pekarangan terhadap total pendapatan keluarga.

Qx : Rata-rata total penerimaan rumah tangga dari pemanfaatan lahan pekarangan.

Qz : Rata-rata total pendapatan rumah tangga.

Sedangkan untuk menghitung rata-rata penerimaan dari hasil pemanfaatan pekarangan dan rata-rata pendapatan rumah tangga menggunakan rumus (Sugiyono, 2007):

$\mathrm{x}=\frac{\sum f_{i} x_{i}}{\sum f_{i}}$

dimana:

$\mathrm{x}$ : rata-rata hitung data berkelompok

$f i$ : frekuensi data ke-i

$x i$ : nilai tengah kelas ke-i

\section{HASIL DAN PEMBAHASAN}

Pola pemanfaatan lahan pekarangan

Hasil penelitian yang telah dilakukan di Desa Tambakrejo Kecamatan Jombang Kabupaten Jombang menunjukkan pola pemanfaatan lahan pekarangan oleh penduduk Desa Tambakrejo cukup beragam. Responden berdasarkan pola pemanfaatan lahan pekarangan dapat dilihat pada tabel 1 .

Tabel 1. Pola pemanfaatan lahan pekarangan

\begin{tabular}{llcc}
\hline Klasifikasi & Keterangan & Frekuensi & Persentase \\
\hline Luas lahan pekarangan & $0-4,59 \mathrm{~m} 2$ (sangat sempit) & 2 & $3 \%$ \\
& $4,61-196,86 \mathrm{~m} 2$ (sempit) & 72 & $75 \%$ \\
& $196,87-389,14 \mathrm{~m} 2$ (sedang) & 12 & $12 \%$ \\
& $389,15-581,42 \mathrm{~m} 2$ (luas) & 10 & $10 \%$ \\
\hline Bentuk pemanfaatan & Pertanian/Perkebunan & 64 & $67 \%$ \\
& Peternakan & 1 & $1 \%$ \\
& Badan usaha lainnya & 31 & $32 \%$ \\
& Lahan kosong & - & - \\
\hline Lama pengelolaan & Kurang dari 1 tahun & 5 & $6 \%$ \\
& 1,1 tahun -3 tahun & 31 & $32 \%$ \\
& 3,1 tahun -5 tahun & 31 & $32 \%$ \\
& 5,1 tahun keatas & 29 & $30 \%$ \\
\hline
\end{tabular}

Sumber: Hasil olahan data primer 2021

Hasil penelitian menunjukkan sebagian besar penduduk Desa Tambakrejo memiliki lahan pekarangan kategori sempit (75\%). Hal ini dikarenakan Desa Tambakrejo termasuk wilayah yang memiliki kepadatan penduduk tinggi. Dilihat dari keadaan geografis Desa Tambakrejo memiliki luas daerah 1,78 km2 serta jumlah penduduk 12.279 jiwa dengan total kepadatan penduduk 6.898 jiwa pada setiap $\mathrm{km} 2$. Adapun total luas lahan menurut penggunaannya adalah sebesar 171,44 ha yang terbagi atas pemukiman 85,94 ha, kawasan industri 0,30 ha, sawah 82 ha, dan lainnya 3,20 ha (BPS Kabupaten Jombang, 2020).

Tabel 1 menunjukkan sebagian besar penduduk Desa Tambakrejo memanfaatkan lahan pekarangan dalam bentuk pertanian/perkebunan (67\%) seperti ditanami bunga, tumbuhan hortikultura, hidroponik, dan toga. 
Bentuk usaha lainnya (32\%) seperti toko kitab, warung makan, kios, konter handphone, kafe dan bengkel. Peternakan (1\%) seperti kolam ikan gurame. Hal ini menunjukkan mayoritas penduduk Desa Tambakrejo sudah melakukan pemanfaatan pekarangan, meskipun masih dalam kondisi yang terbatas. Optimalisasi lahan pekarangan dapat dilakukan dengan melakukan penanaman sayur dan buah, baik dengan penanaman langsung maupun menggunakan polybag (Nurwati, 2015). Pekarangan bukan hanya untuk menciptakan keindahan dan keasrian tetapi dapat dimanfaatkan untuk menanam tanaman seperti sayuran, bumbu dapur, obat-obatan, tanaman hias serta bisa digunakan untuk membudidayakan ikan dengan membuat kolam yang disesuaikan dengan luasan dari lahan pekarangan (Ayu dkk., 2019). Pemanfaatan lahan pekarangan untuk tanaman pangan, ternak, ikan dan lainnya berpotensi dapat memenuhi kebutuhan keluarga (Rohmanugraha, 2018).

Modal awal untuk pemanfaatan lahan pekarangan

Pada penelitian yang telah dilakukan di Desa Tambakrejo Kecamatan Jombang Kabupaten Jombang. Responden berdasarkan modal awal untuk pemanfaatan lahan pekarangan dapat dilihat pada tabel 2 sebagai berikut:

Tabel 2.Modal awal untuk pemanfaatan lahan pekarangan

\begin{tabular}{llcc}
\hline Klasifikasi & Keterangan & Frekuensi & Persentase \\
\hline Modal & $0-500.000$ (sangat kecil) & 49 & $51 \%$ \\
& $510.000-1.000 .000($ kecil) & 17 & $18 \%$ \\
& $1.100 .000-1.500 .000$ (sedang) & 8 & $8 \%$ \\
& 1.500 .000 keatas (besar) & 22 & $23 \%$ \\
\hline Sumber Modal & Tanpa modal & 30 & $31 \%$ \\
& Uang sendiri & 66 & $69 \%$ \\
& Pinjam saudara & - & - \\
& Pinjam Bank & - & - \\
\hline
\end{tabular}

Sumber: Hasil olahan data primer 2021.

Modal merupakan sekumpulan harta yang digunakan untuk membangun suatu usaha. Berdasarkan data pada tabel 2 diatas menunjukkan sebagian besar penduduk Desa Tambakrejo menggunakkan modal sangat kecil $(51 \%)$ dengan sumber modal yang berasal dari uang sendiri $(69 \%)$. Melihat data tersebut, pemanfaatan lahan pekarangan yang dilakukan oleh penduduk Desa Tambakrejo masih belum begitu besar. Hal ini dikarenakan belum pernah diadakannya sebuah kegiatan pendampingan pembelajaran tata cara mengelola lahan pekarangan dengan baik agar lebih produktif oleh pemerintah setempat. Modal sangat berperan penting dalam menentukan dan mengembangkan suatu usaha pemanfaatan lahan pekarangan (Chanlis, 2019).

Kontribusi penerimaan hasil pemanfaatan lahan pekarangan terhadap total pendapatan rumah tangga

Tabel 3. Kontribusi penerimaan hasil pemanfaatan lahan pekarangan terhadap total pendapatan rumah tangga

\begin{tabular}{lccc}
\hline \multirow{2}{*}{ Bentuk pemanfaatan } & \multicolumn{3}{c}{ Rata-rata } \\
\cline { 2 - 4 } & $\begin{array}{c}\text { Penerimaan dari pekarangan Pendapatan non pekarangan } \\
\text { per bulan }\end{array}$ & \multirow{2}{*}{ Total $(\%)$} \\
\hline Pertanian/perkebunan & 571.406 & 2.904 .687 & $16,44 \%$ \\
Peternakan & 2.005 .000 & 3.950 .000 & $33,67 \%$ \\
Badan Usaha Lainnya & 2.198 .548 & 3.691 .935 & $37,32 \%$ \\
Lahan kosong & - & - & - \\
\hline Total & $\mathbf{4 . 7 7 4 . 9 5 4}$ & $\mathbf{1 0 . 5 4 6 . 6 2 2}$ & \\
\hline Sumber: & &
\end{tabular}

Sumber: Hasil olahan data primer 2021

Untuk menentukan kontribusi lahan pekarangan keseluruhan dihitung dengan :

$$
\begin{aligned}
& \text { Kontribusi pekarangan }(\mathrm{P})=\frac{\text { rata }- \text { rata penerimaan }(\mathrm{Qx})}{\text { rata }- \text { rata penerimaan }(\mathrm{Qx})+\text { rata }- \text { rata pendapatan }(\mathrm{Qz})} \times 100 \% \\
& \mathrm{P}(\%)=\frac{4.774 .954}{4.774 .954+10.546 .622} \times 100 \% \\
& \mathrm{P}(\%)=31,16 \%
\end{aligned}
$$

Pada tabel 3. menunjukkan bahwa jumlah kontribusi penerimaan pemanfaatan lahan pekarangan terhadap total pendapatan rumah tangga di Desa Tambakrejo dalam bentuk pemanfaatan pertanian/perkebunan 16,44\%, 
peternakan 33,67\%, dan badan usaha lainnya 37,32\%. Bentuk pemanfaatan pertanian/perkebunan memiliki jumlah presentase pengelolaan yang paling banyak, akan tetapi rata-rata penerimaan yang didapat dari hasil pemanfaatannya sangat kecil berbanding terbalik dengan bentuk pemanfaatan badan usaha lainnya jumlah presentasenya lebih kecil, akan tetapi jumlah penerimaan dari hasil pemanfaatannya lebih besar daripada bentuk pemanfaatan pertanian/perkebunan.

Hal ini disebabkan penduduk Desa Tambakrejo dalam memanfaatkan lahan pekarangan dalam bentuk pertanian/perkebunan dirasa 1) kurang optimal, meskipun banyak yang memilih untuk memanfaatkan lahan pekarangan dalam bentuk pertanian/perkebunan, belum ada pengetahun secara lebih yang dimiliki penduduk Desa Tambakrejo tentang pengelolaan lahan pekarangan dalam bentuk pemanfaatan pertanian/perkebunan agar lebih produktif 2) belum pernah diadakan penyuluhan oleh pemerintah setempat tentang bagaimana tata cara pengelolaan lahan pekarangan agar lebih produktif serta menjadi sebuah peranan penting dalam nilai tambah ekonomi keluarga 3) kurang tepat sasaran, mengingat Desa Tambakrejo merupakan sebuah wilayah asrama pondok pesantren, dengan memanfaatkan lahan pekarangan dalam bentuk pertanian/perkebunan dirasa kurang tepat sasaran. Tiga hal ini yang menjadi penyebab menjadi faktor utama mengapa bentuk pemanfaatan lahan pertanian/perkebunan memiliki kontribusi yang sedikit dibandingkan dengan bentuk pemanfaatan badan usaha lainnya.

Dilihat dari sudut pandang agribisnis, dalam pemanfaatan lahan pekarangan bentuk pertanian/perkebunan merupakan sebuah peluang tersendiri bagi penduduk Desa Tambakrejo untuk mendapatkan penerimaan yang lebih besar jikalau pemanfaatan serta tata cara pengelolaannya dilakukan dengan benar. Beberapa pemanfaatan seperti budidaya sayur dengan menggunakkan sistem tanam hidroponik, vertikultur, dan aquaponik. Hasil sayuran yang telah dibudidayakan dapat dijual ke asrama pondok pesantren untuk menyuplai kebutuhan pokok makanan sehari-hari. Alhasil pihak pondok pesantren tidak perlu keluar Desa Tambakrejo untuk mencari kebutuhan seperti sayuran, pihak asrama pondok pesantren bisa membeli sayur milik penduduk Desa Tambakrejo, dimana hasilnya bisa dijamin lebih sehat dan tidak perlu khawatir akan terpapar covid19. Hal ini merupakan sebuah formula yang cukup bagus seandainya dilakukan oleh penduduk Desa Tambakrejo yang menanfaatkan pekarangannya dalam bentuk pertanian/perkebunan, penduduk Desa Tambakrejo bisa fokus mengelola tanamannya agar hasil panennya berkualitas dan tentunya sehat. Tidak perlu khawatir jikalau sudah waktunya panen, hasilnya akan dijual kemana dan bingung bagaiamana cara menjualnya. Karena segmentasi paasar dari budidaya sayuran yang dilakukan oleh penduduk Desa Tambakrejo sudah sangat tepat dan sangat menguntungkan antara pihak pondok pesantren dengan penduduk Desa Tambakrejo dalam hal memenuhi kebutuhan sehari-hari.

Adapun total keseluruhan kontribusi penerimaan pemanfaatan lahan pekarangan terhadap total pendapatan rumah tangga di Desa Tambakrejo adalah sebesar 31,16\%. Kontribusi adalah jumlah sumbangan pendapatan yang diperoleh responden dari sumber pendapatan pemanfaatan lahan pekarangan terhadap pendapatan rumah tangga yaitu didapat dari selisih antara rata-rata pendapatan dari hasil pemanfaatan lahan pekarangan dengan ratarata total pendapatan rumah tangga responden (Djamalu dkk., 2014).

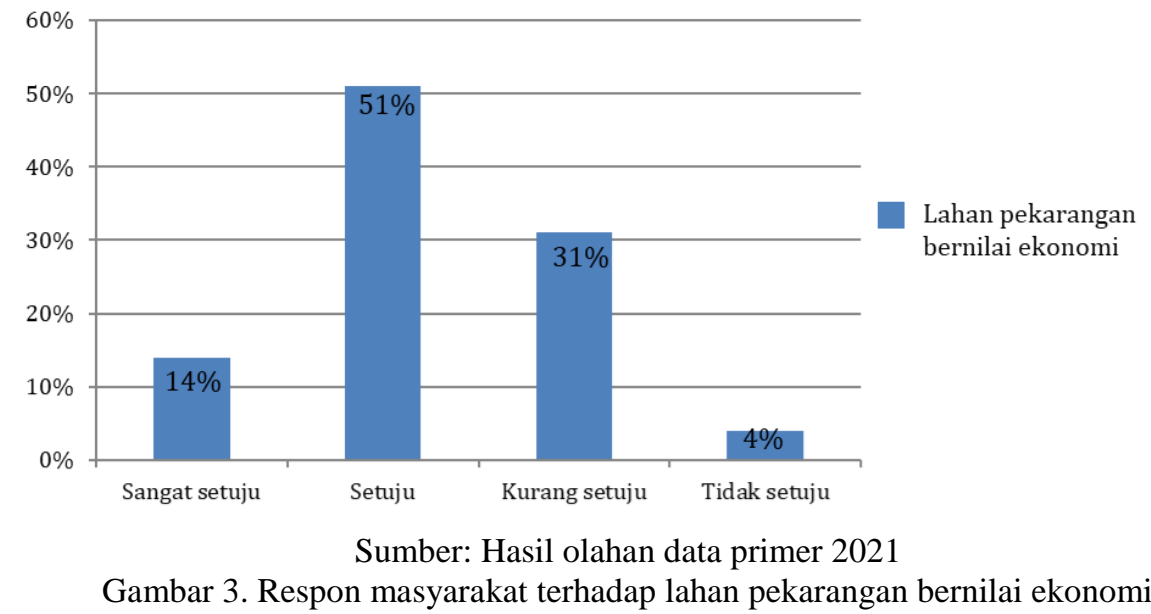

Sebagian besar penduduk Desa Tambakrejo menyatakan bahwa lahan pekarangan sangat bernilai ekonomi, hal ini dapat dilihat pada gambar 3 diatas menunjukkan (51\%) menyatakan setuju. Hal tersebut membuktikan, dengan memanfaatkan lahan pekarangan dapat menambah pemenuhan kebutuhan keluarga walaupun nilainya belum terlalu besar. Melalui pemanfaatan pekarangan dengan perencanaan serta penataan yang baik dapat meningkatkan pendapatan keluarga yang pada akhirnya dapat mendorong tercapainya ketahanan dan kemandirian pangan serta kesejahteraan keluarga (Astuti \& Honorita, 2012). 


\section{KESIMPULAN}

Dari hasil penelitian diperoleh beberapa kesimpulan antara lain:

1. Bentuk pemanfaatan lahan pekarangan yang dilakukan oleh penduduk Desa Tambakrejo sebagian besar adalah pertanian/perkebunan (67\%), badan usaha lainnya (31\%), peternakan (1\%). Tidak ada lahan yang dimanfaatkan sebagai lahan kosong.

2. Sebagian besar $51 \%$ responden menggunakkan modal yang sedikit dari uang sendiri $69 \%$.

3. Adapun kontribusi penerimaan pemanfaatan lahan pekarangan terhadap pendapatan rumah tangga di Desa Tambakrejo Kecamatan Jombang Kabupaten Jombang adalah sebesar 31,16\%. Apabila dihitung dari masing-masing bentuk pemanfaatan pertanian/perkebunan $(16,44 \%)$, badan usaha lainnya $(37,32 \%)$, peternakan $(33,67 \%)$.

\section{DAFTAR PUSTAKA}

Astuti, U. P., \& Honorita, B. (2012). Studi Ekonomi Pemanfaatan Lahan Pekarangan Melalui Penerapan Model Kawasan Rumah Pangan Lestari di Kota Bengkulu. Prosiding Seminar Inovasi Teknologi Pertanian Spesifik Lokasi Mendukung Empat Sukses Kementerian Pertanian di Provinsi Bengkulu, 233-237.

Ayu, Y., Manganang, P., Saselah, J., \& Malupite, B. (2019). Pemanfaatan Potensi Lahan Pekarangan Di Kampung Barangkalang Dengan Menerapkan Konsep Minahortikultura Dan Vertiminaponik Untuk Ketahanan Pangan. Jurnal Ilmiah Tatengkorang, 3(11), 72- 75.

BPS Kabupaten Jombang. (2020). Kecamatan Jombang dalam Angka 2020. In Badan Pusat Statistika (hal. 73).

Chanlis Ozi Harsakti, Eri Sayamar, Y. A. (2019). Analisis Pemanfaatan Lahan Pekarangan Di Desa Sidomulyo Kecamatan Lirik Kabupaten Indragiri Hulu. Jurnal Jom Faperta, 1, 1- 9.

Djamalu, R., Rauf, A., \& Saleh, Y. (2014). Analisis Pemanfaatan Pekarangan Terhadap Pendapatan Rumah Tangga Petani Hortikultura Di Kecamatan Bulango Selatan. Jurnal Agrinesia, 3(3), 1-9.

Gatot Sasongko. (2010). Pengantar Ilmu Ekonomi (H. Siswanto (ed.)). Tisara Grafika Jl. Diponegoro 98 D Salatiga 50714 - Jawa Tengah Telp.: 0298-321798 | Fax : 0298- 321798.

Handayani, M., \& Artini, N. (2009). Kontribusi Pendapatan Ibu Rumah Tangga Pembuat Makanan Olahan Terhadap Pendapatan Keluarga. Jurnal Piramida, 5(1).

Irwan, S. N. R., Rogomulyo, R., \& Trisnowati, S. (2018). Pemanfaatan Pekarangan Melalui Pengembangan Lanskap Produktif di Desa Mangunan, Kabupaten Bantul Yogyakarta. Jurnal Ilmu Pertanian Indonesia, 23(2), 148-157. https://doi.org/10.18343/jipi.23.2.148

Khairunnisa. (2018). Potensi Ekonomi Pemanfaatan Lahan Pekarangan di Kelurahan Sidodadi Kecamatan Wonomulyo Kabupaten Polewali Mandar. In Skripsi Fakultas Ekonomi dan Bisnis Islam Universitas Islam Negeri Alauddin Makassar (Vol. 1, Nomor 1). UIN Alauddin Makassar.

Nurwati, N. (2015). Analisis Pemanfaatan Pekarangan Untuk Mendukung Ketahanan Pangan di Kecamatan Rumbai Pesisir Kota Pekanbaru. Jurnal Ilmiah Pertanian, 11(2), 1-8.

Rohmanugraha, D., \& M, I. L. (2018). Optimalisasi Pemanfaatan Pekarangan Rumah dengan Sistem Vertikultur dari Limbah Plastik Sebagai Upaya Mendukung Indonesia Bebas Sampah dan Mewujudkan Ketahanan Pangan Keluarga di Dukuh Baturan Kec. Gantiwarno Kab. Klaten. Jurnal Aplikasi Ilmu-ilmu Agama, $18(2), 127$.

Sugiyono. (2007). Statistik Untuk Penelitian (E. Mulyatiningsih (ed.); Ke-12). CV Alfabeta. J1. Geger Kalong Hilir No.84 Bandung 40153.

Sugiyono. (2012). Metode Penelitian Kuantitatif, Kualitatif, dan R\&D (Ke-19). CV Alfabeta. Jl. Geger Kalong Hilir No.84 Bandung 40153. 